\title{
Las historias personales perdidas: «lo húngaro» y el teatro del Siglo de Oro (interpretación y cercanía de la lejanía física)
}

\section{The Lost Personal Stories: Hungarians in Spanish Golden Age Theatre (Interpretation and Proximity of Distances)}

\section{Zoltán Korpás}

Universidad ELTE, Budapest

HUNGRÍA

zkorpas@t-online.hu

[Hipogrifo, (issn: 2328-1308), 2.2, 2014, pp. 43-61]

Recibido: 18-12-2013 / Aceptado: 30-04-2014

DOI: http://dx.doi.org/10.13035/H.2014.02.02.04

Resumen. Hungría y lo húngaro parecen ser un tema profundamente divulgado en la literatura española del Siglo de Oro pese a la distancia física de los dos reinos. El estudio rastrea las razones interculturales que podrían haber causado una mayor representación de «lo húngaro» entre los temas literarios de aquel entonces. Aparte de los paralelismos más o menos evidentes - como el hecho de pertencer a la misma dinastía, el desafío que significaba el avance otomano tanto para la Monarquía Católica como para el Reino de Hungría o formar parte de la misma «Universitas Christiana»-, dan muestra de las finas redes de historias personales de los miles de españoles que luchaban en Hungría contra los otomanos, participaron en misiones diplomáticas o que bien formaron parte de la corte real de los Austrias de Viena. La introducción de las historias personales revela la envergadura de la atención hacia lo húngaro por parte el público español de aquel entonces y presenta las raíces fundamentales del porqué de ese atractivo, así como la percepción e interpretación por parte de los genios de la literatura del Siglo de Oro de los temas relacionados con Hungría.

Palabras clave. Relaciones interculturales, españoles en Hungría en los ss. XVIXVII, temas húngaros en la literatura del Siglo de Oro.

Abstract. Despite of the geographical distances between the two kingdoms, both Hungary and the hungarians seem to be topics widely spreaded in the Span- 
ish literature of the Golden Age. The study tracks the intercultural reasons which might have caused this vast representation of the Hungarians among the literature topics of those centuries. Besides the more or less evidents paralelisms -like the fact of being ruled by the same dynasty, the big challenge represented by the Ottoman expansion both for the Catholic Monarchy and Kingdom of Hungary or being part of the same «Universitas Christiana» - the study shows the very thin nets of the less known personal histories of the thousands of Spaniards fighting against the Ottomans in Hungary. They were there taking part in diplomatic missions or being members of the imperial Court as well as of the Eastern Habsburgs. The presentation of personal histories demonstrates the magnitude of the attention of the Spanish public towards the happenings in Hungary and it shows the fundamental roots both of this specific interest in Hungarian topics and the perception and interpretation the genius of the Spanish Golden Age literature have of it.

Keywords. Intercultural Relationships, Spaniards in Hungary in XVI-XVIIth Century, Hungarian Topics in Spanish Literature of Early Modern Age.

No ha de sorprender que las relaciones entre España y Hungría nunca hayan sido intensas. Pero, ¿cómo podemos interpretar que durante el Siglo de Oro ciertos dramaturgos, incluyendo el mismo Lope de Vega con aproximadamente 20-25 piezas ${ }^{1}$, pusieran en escena muchas obras relacionadas con lo «húngaro»? ¿Será suficiente en la búsqueda por la respuesta centrarnos en las dinastías reinantes de ambos territorios, o en el paralelismo del desafío común, es decir, el avance otomano por el Mediterráneo y por el continente, donde el mayor peso de la resistencia caía tanto sobre los hombros de España como sobre los de Hungría? O bien, junto con estos factores importantes, podemos encontrar un nivel mucho más personal, el de la «microhistoria» que nos hace entender porqué le interesaban a la literatura áurea española temas aparentemente tan distantes como Hungría y los húngaros. En este breve ensayo intento dar una respuesta a estas cuestiones que podrán servir como base para la interpretación de las obras literarias relacionadas con Hungría. En las últimas décadas surgieron ciertos estudios que interpretaron algunas obras literarias del Siglo de Oro, empezando con el texto de Joseph Peter Bocsi e incluyendo mi artículo previo sobre la pieza El rey sin reino de Lope de Vega y, recientemente, algunos análisis sobre ciertas piezas del dramaturgo aurisecular².

Como afirma Dezső Csejtei en su artículo sobre Ortega y Gasset, las relaciones entre los dos reinos distantes siempre se han caracterizado por ser «tan finas como una telaraña y que estos delicados hilos nunca han llegado a constituir un lazo fuerte, capaz de crear una tradición» ${ }^{3}$. En cierta medida, comparto dicha opinión subrayando que sí existía una época menos conocida, incluso para la mayoría de los científicos de Historia Cultural Comparada, de cuando las relaciones entre los

1. Ver Bocsi, 1967, p. 96

2. Sobre lo húngaro en el teatro de Lope de Vega ver la obra citada de Bocsi, 1967, pp. 95-103. También Sambrian, 2010, pp. 947-955; Gutiérrez Gil, 2013, pp. 218-234; Gómez, 2011, pp. 1947-1963; Cuerva, 2006, pp. 277-299; incluyendo mi artículo anterior: Korpás, 1999a, pp. 119-127.

3. Csejtei, 2008 , p. 53 
dos territorios eran sorprendentemente estrechas, numerosas y muy personales - complementadas por los paralelismos ideológicos y dinásticos-, llegándose a crear una sensación de cercanía para el público del Siglo de Oro con respecto a lo «húngaro». Este período coincide con la plenitud de la expansión de la Monarquía Católica durante los Austrias mayores (Carlos $\vee$ y Felipe II) y queda reflejado en la literatura de la época de los Austrias menores.

Un extraño símbolo acerca de la precisión y desconocimiento de esas relaciones lo ofrecen los retablos de la Iglesia de San Antonio de los Alemanes, sita en la madrileña calle de los Tudescos. Se trata de una iglesia dedicada a San Antonio de Padua y que cambió su nombre en 1668 con la llegada de la esposa de Carlos II, Mariana de Neoburgo, cuando la iglesia fue otorgada al séquito alemán de la reina. Los retablos de la iglesia encarnan a diferentes reyes santos de la Cristiandad, incluyendo San Fernando de Castilla, San Luis de Francia, San Enrique de Alemania y dos santos reyes de Hungría: San Esteban, primer rey cristiano de Hungría y su hijo, el príncipe San Emerico. Se desconoce la razón por la que aparecen en una iglesia dedicada a los alemanes solo un santo rey alemán y, en cambio, los dos santos principales de Hungría. Este hecho podría reflejar que, para el público del Siglo de Oro, Hungría se mostraba más cercana y comprensible que para el de los siglos $\mathrm{XX}-\mathrm{XXI}$.

Pero vayamos por partes. Durante los largos siglos de la Antigüedad, Edad Media y Edad Moderna, tanto la Península Ibérica como la cuenca de los Cárpatos fueron zonas de choque de civilizaciones. Lo que nos importa especialmente en este ensayo, es subrayar que durante el Renacimiento y el Barroco ambos territorios fueron parte de la misma «Universitas Christiana» y, en sus autodefiniciones contemporáneas, se prestaban a similares conceptos ideológicos: el concepto de «baluarte de la cristiandad» formaba parte no solo de la ideología y concepción de la misión cristiana para los españoles y húngaros, sino también de la autodefinición moderna de todas aquellas naciones y reinos que se hallaban en zonas de choques entre el mundo otomano y cristiano, destacando el reino de Polonia, o bien los dos principados rumanos de Valaquia y Moldavia, e igualmente el territorio de los serbios, croatas, o incluso el de los austriacos ${ }^{4}$.

Entretanto, la idea de caballería y su relación con el «miles Christi» y la «cruzada» formaban parte de la realidad diaria de la sociedad del Siglo de Oro, los cuales se manifestaban a través de las instituciones de la Monarquía Católica. Ello se dio especialmente mediante la profunda penetración social de las órdenes de caballería hispánicas (Santiago, Alcántara, Calatrava, Montesa, etc.), a lo que se unía el concepto de «cruzada», manifestado también en impuestos de cruzada, bulas, limonsnas y procesiones. Un similar concepto surgió en la Hungría que se hallaba en lucha contra la invasión otomana: la defensa de los castillos húngaros recaía en mayor parte sobre la guarnición húngara y la extranjera (bohemios, alemanes, italianos, valones y también españoles). La táctica de las luchas en la tupida red de fortalezas en Hungría requería un tipo de guerra muy especial, semejante a las de

4. Knoll, 1974, pp. 381-401. Sobre Ragusa, ver Kunčević, 2013, pp. 37-68; sobre Polonia, ver Gregorowicz, 2013; sobre Polonia y Hungría el libro de Hopp, 1992. 
Flandes o las de la Reconquista española previa a 1492: los largos asedios, grandes guerras (expediciones de mayores ejércitos) eran escasos y la «pequeña guerra» de asaltos rápidos, infiltraciones o la captura de «lenguas» (espionajes) era la realidad diaria ${ }^{5}$. Es obvio que la caballería ligera parecía ser la más apta para similares fines: en la Hungría del siglo XV-XVII surgió una capa social muy especial que incluía por una parte miembros de la caballería ligera (los llamados «húsares», similares a los jinetes de la historia militar española) y, por otra parte, los soldados de a pie, ambos denominados «vitéz» (soldado «valiente» O «galante»). A dicha gente - descrita en los inolvidables versos del poeta renacentista Bálint Balassi o por el rival del general Raimondo Montecuccoli, Miklós Zrínyi- se le atribuía valentía cristiana, bravura, honestidad y piedad muy similar al ideal caballeresco hispano del teatro del Siglo de Oro y, a la vez, rasgos típicamente húngaros relativos al vestido y la apariencia ${ }^{6}$. Como tal, era un fenómeno de fácil identificación para un lector hispano.

Aparte de los paralelismos de autodefinición, se ha de mencionar también que ambos reinos eran gobernados por la misma dinastía de los Austrias. Entre las dos ramas existía un vasto enlace tanto a nivel de política dinástica como de la realidad diaria de las sociedades. La intensidad de las relaciones oscilaba según la dinámica de la gran política, pero a un nivel general podemos afirmar que durante el período de gobierno de la misma dinastía (entre la llegada al trono de Fernando I de Austria en 1526 y el fallecimiento de Carlos II de Austria en 1700) Ias relaciones entre España y Hungría fueron sorprendentemente estrechas, sobre todo entre 1526-1556, cuando el cabeza de la dinastía, Carlos, se sintió obligado de reforzar la soberanía de su hermano menor Fernando en los reinos de Hungría y Bohemia, recientemente adquiridos. Más tarde, cuando las dos ramas de la Casa de Austria decidieron formar dos imperios independientes pero en cooperación, la intensidad de las relaciones entre Hungría y España disminuyó y su carácter también se alteró. Como veremos más adelante, durante la primera mitad del siglo XVI destacaba la presencia de soldados españoles en los campos de batalla húngaros con el objeto de defender la dinastía y su soberanía contra los otomanos y otros pretendientes en tierras conquistadas. Pero en la segunda mitad del siglo XVI y primeras décadas del siglo XVII cuando los confines de la Hungría Real ya quedaron más o menos fijados, eran otros los desafíos que fomentaban el conocimiento sobre Hungría en la Península. Como consecuencia de la Contrarreforma, aparecieron los primeros jesuitas en el reino magiar, algunos españoles entre ellos, trayendo noticias desde aquella tierra lejana y exótica a la Monarquía Católica. Del mismo modo, comenzaron a surgir jesuitas húngaros pensionados al servicio de la Monarquía Católica. El jesuita Alonso Carrillo, cumpliendo misiones en Praga, Italia y España al servicio de Segismundo Báthory, príncipe de Transilvania durante el período comprendido entre 1588-16027, contribuyó en gran medida a la difusión de información en España, la cual llamó la atención de Lope de Vega al escribir la pieza «Prodigioso príncipe

5. Dávid-Fodor, 2000; Pálffy, 2009a y 2009b.

6. Bayerle, 1982, pp. 227-242; Zachar, 2000, pp. 117-159 y Perjés, 1982, pp. 335-349.

7. Primer gobierno: marzo de 1588 hasta julio de 1594, $2^{\circ}$ gobierno: agosto de 1594 hasta marzo de 1598, $3^{\text {er }}$ gobierno: agosto de 1598 hasta marzo de 1599 y $4^{\circ}$ gobierno: 1601-1602. 
transilvano» ${ }^{8}$. Algunas décadas después, otro jesuita, el cardenal Péter Pázmány - persona destacada del mundo magiar y relacionado estrechamente con la Contrarreforma y los jesuitas de Hungría- realizó misiones en Roma por encargo del rey Felipe IV ${ }^{9}$.

Los contactos diarios ejercieron cierta influencia a nivel personal, que a través de relaciones, cuentos o chismes, pudieron llegar a oídos de la gente atraída por lo exótico. En este contexto, se ha de mencionar -como posible fuente para temas teatrales- que durante la Guerra de los Treinta Años hubo una guarnición húngara de 1820 soldados apostada en el Milanesado ${ }^{10}$. Es menos conocido aún que las guerras de Flandes y la Guerra Larga o Guerra de los Quince Años en Hungría (1591/1593 -1608) estaban en cierta correlación: los generales y maestres de campo usaban las mismas zonas de reclutamiento en Alemania para ambas regiones militares, causando problemas temporales para el uno y el otro por falta de nuevos reclutas en logística militar. Incluso tenemos constancia de que enviaban soldados de diferentes naciones y generales de Flandes a Hungría o viceversa, pues en ambas regiones se necesitaba experiencia militar muy similar (solo mencionando algunos de los más destacados que aparecían en ambas regiones: el italiano Giovanni Baptista Castaldo y el español Álvaro de Sande de la primera mitad del s. XVI, o de otra época: el albanés-italiano Giorgio Basta, el príncipe Felipe Emanuel de Lorraine, el duque de Mercœur, el bohemio Adolf von Schwarzenberg de los años de la Larga Guerra Turca) $)^{11}$. Y tampoco olvidemos el último aspecto: la participación de los casi 700 voluntarios españoles en la reconquista de Buda en 1686, que formando parte del ejército cristiano ofrecieron su sangre y vida por la liberación de la sede real húngara. Incluso, el duque de Béjar falleció ante las murallas, después de haber provocado un ataque imprevisto y acelerado. $\mathrm{O}$ sea, a través de las interacciones de la gente militar -como parte de la tradición oral- se extendían informaciones sobre Hungría, que podrían atraer la atención de los escritores para incorporarlas en sus obras.

El ejemplo por excelencia de la incorporación de los húngaros al panteón español podrían ser las diferentes interpretaciones de la figura histórica de János Hunyadi, conocido en ciertas fuentes españolas como Juan Huniades. La familia Hunyadi era una de las más importantes no solo de Hungría, sino de Europa Central del siglo XV. János era el héroe máximo de la cristiandad, temido por los otomanos quien solo tres años después de la caída de Constantinopla, en 1456 llegó a triunfar sobre el ejército invencible del sultán Mehmed II en Belgrado (parte de Hungría en aquel entonces). Aunque Juan había fallecido a consecuencia de la peste en Belgrado, su hijo Matías Hunyadi llegó a ser coronado dos años después, en 1458, rey de Hungría y estableció su corte con rasgos renacentistas casándose con Beatriz de

8. Szilas, 2001; Veress, 1943

9. Martí, 2011, pp. 175-205 y 2009, pp. 473-526; Monostori, 2008a, pp. 351-366 y 2008a, pp. 303-315.

10. Martínez Ruiz, 2008. p. 897

11. Los paralelismos de las guerras de Hungría de los Austrias de Viena y la guerra de Flandes de la Monarquía Católica parecen ser evidentes y sorprendentes, además de desconocidos hasta hoy. Podría servir como tema de otra investigación el presentar de forma estructurada aquellos paralelismos. 
Aragón, de la rama de Nápoles. El poderío real, la brillantez de la corte, fue admirado por Europa, el rey mismo llamado Matías Corvino - gracias al cuervo negro con un anillo de oro en su pico que figuraba en el escudo de los Hunyadi. Las hazañas de los miembros de la familia de los Hunyadi fueron contadas por cronistas de origen italiano y húngaro, como por ejemplo Antonio Bonfini o Johannes Thuróczy. Gracias al parentesco de su esposa con la casa de Aragón, su fama fácilmente llegó a través de Nápoles a España y pocas décadas después de la victoria de Belgrado fue publicada la novela caballeresca de Joan Martorell, el Tirant lo Blanch. Según algunos expertos la figura mítica de Tirante se basa en la figura histórica de János Hunyadi $^{12}$. El héroe húngaro de las luchas anti-otomanas mantuvo correspondencia con ciertos españoles, como por ejemplo con el cardenal Carvajal, con el papa Calisto III (Alfonso Borja) y con el rey Alonso V el Magnámino. Incluso, según algunos, ofreció sus servicios al rey de Aragón para que el soberano le ayudara en su lucha contra los otomanos. El general húngaro fue llamado en ciertos casos Valachus - Balachus, debido a su nacimiento en Valaquía. En crónicas francesas aparece como el chevallier Blanc o como el rey Blanco. Además, el símbolo de la casa de los Hunyadi fue el cuervo -lo mismo que aparece en el escudo de Tirant en el capítulo 125 de Martorell. El hijo de Hunyadi, el rey Matías de Hungría es conocido también como Matías el Corvino - del animal corvus (lat.). Y para concluir: en el momento de su muerte tanto Hunyadi como Tirant fueron atendidos por frailes franciscanos. En caso del primero - su íntimo amigo, el fraile San Juan Capistrano ${ }^{13}$-. Más de cien años después, Lope de Vega también añade una obra a la memoria de los Hunyadi en España, escribiendo su pieza El rey sin reino. En esta obra Juan Huniades no solo se hispaniza gracias a su nombre, sino que además Lope explícitamente lo acerca al público español, inventando una descendencia ficticia del héroe cristiano: «este transilvano / medio español por su madre» ${ }^{14}$.

Refiriéndose a las palabras citadas de Csejtey: las relaciones hispano-húngaras aparecieron en los siglos XVI-XVII como una telaraña fina, pero intensa, puesto que dichas relaciones no eran esporádicas, incluso aun podrían crear (una) tradición. Las palabras claves en la identificación de esta tradición son lo militar y la política dinástica, basándose en la defensa de la dinastía en cualquier parte de la «Universitas Christiana» y en la lucha contra los enemigos de la fe.

Durante el verano de 1532, Segismundo el Viejo, el rey de Polonia (1506-1548) en su carta a Carlos V expresó su miedo a que Hungría pudiera caer en manos de los otomanos, perdiendo así un país cristiano importantísimo de la «Universitas Christiana», denominando a Hungría «nobilissimum christianissimum membrum» ${ }^{15}$. Casi cien años más tarde, el Fénix, Lope de Vega en su pieza - de sorpredente realidad histórica- El rey sin reino usa el mismo concepto palabra por palabra: «nación be-

12. Martorell, 1984.

13. Martorell, 1984, ver cap. «Translator's foreword».

14. En realidad la madre de János Hunyadi fue Erzsébet Szilágyi.

15. Segismundo a Carlos V, Cracovia, 15 de junio de 1532, Archivo General de Simancas (AGS), Estado Alemania, leg. 636, fol. 204: «Hungariam nobilissimum christianissimum membrum ab imminenti interitumet reliquem christianem provintiem a metu et trepidacione liberari possunt». 
licosa y noble cristianísima defensa de la fe» para presentar la Hungría de los Hunyadi a su público lector ${ }^{16}$. Estos dos ejemplos tan lejanos tanto en tiempo, como en espacio, también demuestran la integración de Hungría dentro del mundo percibido por el público español. Incluso, nos ha de sorprender la profundidad de sus conocimientos sobre Hungría (incluyendo en estrofas muy densas todas las condiciones necesarias para ser coronado como rey legítimo de Hungría): «La corona Sacra [...] el Cardenal Dionisio ${ }^{17}$ se la puso [...] / en la Iglesia San Esteban Santo».

El rey de Hungría debe ser coronado con la corona sacra de San Esteban, por el cardenal de Estrigonia y en la iglesia de San Esteban en Székesfehérvár (Alba Regia, Stuhlweißenburg), sacro sitio tradicional de coronación en Hungría, destruido en 1543 por los otomanos.

Un detalle más: hojeando los diferentes aspectos de la manifestación de la soberanía real, después del fallecimiento de Luis II de Jagellones en la batalla de Mohács en 1526, los hermanos Fernando I y Carlos I llegaron a un acuerdo sobre la herencia de la corona de San Esteban. Después de una breve correspondencia acordaron que Carlos no obstaculizaría que, gracias al título del rey de Hungría, el infante y archiduque se convirtiera en soberano independiente de Carlos I (no olvidemos que esa legitimidad que disminuía la dependencia de Fernando de su hermano mayor, solo era accesible a través de la corona de San Esteban, mientras la de Bohemia, como uno de los electores imperiales, no la ofrecía.) Pues bien, pese a esa concesión a favor de Fernando I, el escudo de Carlos I durante muchos años más contenía las franjas roja y de plata del escudo de Hungría, aunque en su titulatura no se mencionaba la posesión de Hungría18.

El público del Siglo de Oro tenía conocimientos sobre Hungría a través de diferentes canales de flujo de información. Algunas de las fuentes son las tradiciones orales, historias personales de los soldados, viajeros españoles que luchaban en Hungría y luego aparecían en las guarniciones de los tercios viejos en Milanesado, Nápoles, en los campos de batallas de Flandes o en los presidios de Magreb. Tenemos constancia de ciertos maestres de campo, como Bernardo de Aldana, Álvaro de Sande o de otros capitanes; alféreces como un tal Ruiseco, Luis de Ordóñez, etc, que defendieron la Cristiandad contra la expansión otomana no solo en el Mediterráneo sino en Hungría también. Esa gente - desconocida en mayor proporciónque servía ambas ramas de la dinastía de los Austria tanto en Europa Central, como en Italia o en las aguas del Mediterráneo, contaron sus experiencias personales a sus conocidos en las guarniciones de Italia, en la corte real en España o en otros terrenos de vida cotidiana peninsular. Es conocido que el teatro de Siglo de Oro se inspiraba por las historias, cuentos y chismes surgidos por las guarniciones, por las

16. Sobre la realidad histórica de la pieza teatral El rey sin reino ver Korpás, 1999a, pp. 119-127.

17. Dénes Széchy, arzobispo de Esztergom (Estrigonia) y primado de Hungría entre 1449 y 1464.

18. Korpás, 2008b, p. 73. Ver también: el gran escudo de armas de Carlos V -a la siniestra del escudo de Jerusalén figura el escudo de Hungría con ocho fajados de gules y plata-. 
calles o tabernas e incluso, por la corte, perpetuando de tal manera las microhistorias en escenas dramatúrgicas ${ }^{19}$.

La historiografía contemporánea también podría servir al propósito: es conocido que el cronista de la corte, Prudencio de Sandoval durante la compilación de su gran obra sobre Carlos $\vee$ tenía acceso a la correspondencia imperial, incluso incluía cartas originales como por ejemplo la carta del rey Luis II de Hungría escrita dostres días antes de la batalla de Mohács. La crónica de Sandoval es rica y correcta en referencias sobre la historia de Hungría de la primera mitad del siglo XVI. Sería menester referirnos también a la crónica de Pero Mexía (Historia Imperial y Cesárea) o de Martín García Cerezeda (Tratado de las campañas y otros acontecimientos de los ejércitos del emperador Carlos V en Italia, Francia, Austria, Berbería y Grecia desde 1521 hasta 1545) en las que hay abundantes referencias sobre los acontecimientos de Hungría. Pero tampoco olvidemos la obra el Antijovio, escrita por el conquistador Gonzalo Jiménez de Quesada. Obra bien extraña, pues el Antijovio (Apuntamientos y anotaciones sobre la historia de Paulo Jovio, 1567) es una reacción a la obra Historiarum suis temporis de Paolo Giovio. La Historia de Giovio es una de las fuentes más importantes de la historia de Europa Central, incluyendo los reinos de Polonia, Bohemia y Hungría. Quesada, a través de su crónica de carácter crítico, dirigida a Jovio, describe sus interpretaciones personales sobre los sucesos húngaros e incluso de vez en cuando confabula historias solo con la intención de oponerse a Jovio. Pese a ello, es sorprendente la riqueza de informaciones sobre Hungría que tenía el fundador de Bogotá persiguiendo su sueño de encontrar El Dorado.

Tenemos constancia también de que Lope de Vega, en su tragicomedia El rey sin reino, reconstruía de una manera muy verosímil la historia de Hungría entre 1439 y 1458, enfocando sobre todo la historia del héroe cristiano Hunyadi y su hijo el rey Matías Corvino. Para ello utilizaba la obra Rerum Hungaricarum decades IV et dimidia de Antonio Bonfini, historiador renacentista de la corte de Matías Corvino y también la Chronica Hungarorum del húngaro Johannes Thuróczy. Debido a que Bonfini era miembro del séquito de la esposa de Matías, Beatriz de Aragón de la rama de Nápoles, podemos suponer que como consecuencia de los enlaces entre Nápoles y la Monarquía Católica podría haber ejemplares divulgados por España que podrían haber llegado también a manos de Lope de Vega ${ }^{20}$.

19. Sobre los españoles que luchaban en Hungría ver: Korpás, 2008b, pp. 205-255 y especialmente la lista de los españoles en Hungría en las pp. 264-298; y también 2004, pp. 335-370.

20. Para el análisis comparativo de la obra de El rey sin reino con las dos crónicas ver Korpás, 1999a, pp.119-127, con especial atención a la transcripción de la prosa de Bonfini en verso: Bonfini: «lesu Christe, federa, que Christiani tui mecum percussere; per numen tuum sancte iurarunt datamque sub nomine tuo fidem violarunt, perfide suum deum abnegarunt. Nunc, Christe, si deus es, ut aliunt et nos hallucinamur, tuas measque hic iniurias, te queso ulciscere et his, qui sanctum tuum nomen nondum agnovere, ex violate fidei poenis ostende».

Lope de Vega:

Jesucristo aquestas son

las paces que tus cristianos

firmaron tener conmigo

HIPOGRIFO, 2.2, 2014 (pp. 43-61) 
Pero «el periodismo» de la Europa del siglo XVI-XVII, las famosas relaciones de sucesos (conocidos en Europa Central en su nombre alemán Neue Zeitung ${ }^{21}$ ) también pueden fomentar el flujo de informaciones de un mundo menos conocido con el objetivo de ganar el favor del público hispano para una misión política. Paralelamente, estos documentos pueden traer abundantes informaciones para inspirar una pieza teatral, como sucedió en el caso de la tragicomedia de El prodigioso príncipe transilvano escrita por Lope de Vega ${ }^{22}$ : la imprenta de Rodrigo de Cabrera en Sevilla publicó la mayoría de las relaciones sobre la Larga Guerra Turca o Guerra de Quince Años en Hungría (1591/1593-1608), influidas por las informaciones transmitidas por el jesuita Alonso Carillo durante sus misiones en Roma y en Madrid siendo agente y consejero de Zsigmond Báthory, príncipe de Transilvania.

También la correspondencia diplomática era abundante en referencias a Hungría. Como ya se ha referido, ciertos cronistas cortesanos tenían la suerte de tener acceso a la correspondencia diplomática y con ello difundían informaciones sobre Hungría entre el público lector. Teniendo en cuenta este aspecto de la diplomacia, se ha de mencionar que las dos ramas de los Austrias mantenían una red diplomática muy estrecha, pero el carácter de las relaciones diplomáticas era diferente comparando la época de Carlos I con la de sus descendientes. Durante el reinado de Fernando I y Carlos I, podemos hablar mejor de una representación dinástica más desequilibrada, en la que Carlos I envíaba mensajeros o agentes solo en caso de necesidad política, mientras que Fernando I mantenía una embajada constante en la corte imperial desde el principio: las misiones de Martín de Salinas y de Juan Alonso de Gámiz duraban décadas ${ }^{23}$. Esa forma de relaciones familiares se reflejó también en la jerarquía interna de los dos Austrias. Con la subida al trono de Felipe II, las relaciones en este sentido serían más equilibradas y ambas dinastías mantuvieron embajadas perpetuas en sus respectivas cortes. Hacia finales del siglo XVI y principios del XVII, destacan embajadores como Hans Khevenhüller en Madrid o Guillén de San Clemente y su sucesor Baltasar de Zuñiga y Velasco en la corte de Praga/Viena. Al hojear la correspondencia podemos declarar que los sucesos en Hungría eran de una temática rica y constante, parte de la gran política dinástica casi de cada carta despachada -en mayoría formaba parte de la cuestión del avance otomano por el continente y el Mediterráneo-.

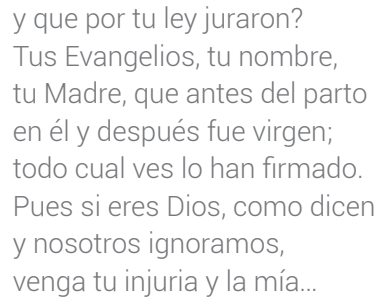

21. Sobre el flujo de informaciones de las guerras anti-otomanas en Hungría ver el libro de la historiadora húngara Etényi, 2003.

22. González Cuerva, 2006, pp. 277-299.

23. Rodriguez Villa, 1903-1905; Aguirre Landa, 2004, pp. 287-307; Cuesta Astobiza, 2002; Korpás, 2009, vol 2, pp. 249-306; vol. 3, pp. 309-372. 
Aparte de la correspondencia diplomática se halla otra telaraña intercultural muy delicada a nivel personal de los cortesanos españoles en la corte de Viena. Según los trabajos del austríaco Christopher Laferl, los séquitos de los reyes y reinas de la época de Fernando I y Maximiliano II incluyeron una copia de los nombres de españoles, sumando casi el $7-10 \%$ de la totalidad de los cortesanos (en total unos 80-100 hispanos) ${ }^{24}$. Como era costumbre en la época, muchos de ellos llegaban con sus parientes, incluyendo hermanos, hijos, esposas o primos etc. Esa gente en busca de fortuna servía al rey en diferentes cargos y misiones palaciegas, diplomáticas o militares. Por otra parte intentaban apoyar a sus compatriotas en su carrera individual, algo que sucede por ejemplo con el maestre de campo Bernardo de Aldana, quien dedicaba diferentes cartas desde los campos de batalla de Hungría al secretario real, Juan de Castillejo (primo del famoso poeta renacentista de Viena, Cristobal de Castillejo), pidiendo al secretario que le ayudara a conseguir el hábito de alguna orden militar de España, indispensable para un hidalgo de su calidad con la intención de lograr éxito social25. Los diplomáticos y cortesanos españoles en Viena eligieron diferentes estrategias personales, o bien volvieron al servicio de la Monarquía Católica, algo que sucede con algunos de los cortesanos como el secretario Juan Alonso de Gámiz, embajador de Fernando I ante Carlos V, o Francisco Lasso de Castilla, cortesano de la infanta Ana de Austria, futura esposa de Felipe II. Uno de los diplomáticos más destacados en el servicio imperial de Hungría era Antonio de Mendoza, quien después de cumplir su misión sería el futuro fundador y primer virrey de México y fallecería como virrey de Perú. Durante la primavera de 1527, Antonio de Mendoza fue el encargado de traer la letra de cambio de 100.000 ducados para socorrer al infante Fernando I después de la batalla de Mohács y muerte del rey Luis II. En la lucha por el trono húngaro, los 100.000 ducados para Fernando -en apuro financiero- supondrían una ventaja muy valiosa contra el otro pretendiente, János Szapolyai, garantizando la superioridad militar durante su invasión de Hungría en junio de $1527^{26}$.

Otros encontraron su fortuna y suerte en la corte de los Austrias orientales, algo que sucede por ejemplo con otro miembro de la noble familia Lasso de Castilla,

\section{Laferl, 1997}

25. Ver las cartas de Bernardo de Aldana escritas a Fernando I: «Lo que al servir suplico a Vuestra Majestad es que me haga merced de algunas letras para el serenissimo principe Maximiliano y para algunos oficiales de la corte y consejo real las quales enbio en memoria al secretario Castillejo para que Su Alteza me mande enbiar en España cien mill maravedis de que Su Majestad me hizo merced en la teniencia de Sedella en la consulta pasada y aunque en Espana no se pagan las tenencias sino de tres en tres anos o veramente por favor particular suelen de tener respeto a los que estan ausento en servicio de Su Majestad.» Léva, 3 de mayo de 1549 y en otra carta: «Suplico a Vuestra Majestad no tome pesadumbre de lo que al presente le quiero suplicar porque si alguna mas autoridad deseo yo espero en Dios que me dara gracia de poder mostrar a Vuestra Majestad como la deseo para poder emplear en su servicio. $Y$ ansi suplico a Vuestra Majestad pues que todos los maestres de campo al presente ay del emperador tienen abitos de las ordenes de Alcantara o Santiago o Calatrava que Vuestra Majestad me favorezca para que yo participe de la mesma autoridad siendo servido de escrevir a Su Majestad por un abito de la orden de Alcantara para mi» Bernardo de Aldana a Fernando I, Szebeléb, 15 de abril de 1549. En Korpás, 1999b, pp. 26, 31. Ver también: OStA HHStA Ung. Akten Allg. Akten Fasc. 55. Konv. C.fol. 78. 26. Korpás, 2008b, pp. 69-79; Korpás, 2000a, pp. 321-337. 
Pedro, asimilándose a la aristocracia imperial casándose con Polixena von Ungnad und Sonnegg. Como ejemplo de asimilación por excelencia, podría servir la historia de la familia imperial von Hoyos. El fundador de la rama germanizada fue un tal Hans von Hoyos, nacido como Juan de Hoyos y casado en 1548 con Judith von Ungnad. Debido a que los Ungnad formaron parte también de la nobleza húngara, con Juan de Hoyos hemos llegado también a los enlaces personales entre ciertos hispanos y la nobleza húngara -en este contexto hago referencia a Martín y Tomás Lazcano-. Ambos sirvieron al rey Fernando en Hungría: Martín fue el capitán de una de las fortalezas más importantes del reino, la de Esztergom (Estrigonia), sede del primado de Hungría, mientras su tío, Tomás llegó a tener el cargo de vicegeneral de Hungría Superior ${ }^{27}$. Martín recibió el título nobiliario húngaro y fue uno de los primeros, precisamente el tercer extranjero, ennoblecido por Fernando I. Esa capa social de nobles de nacimiento extranjero de la «natio hungarica» se llamaba indigenatus.

Sería tema de otro estudio aparte describir detalladamente la presencia de los españoles en Hungría ${ }^{28}$. Resumiéndolo en pocas frases, cabe destacar que la cantidad de los soldados españoles en Hungría es sorprendentemente alta: aparecen unos 10.000-13.000 en un lapso de 30 años (1526-1556). Pero dentro del marco de este ensayo sí que cabe lugar de trazar las características de su presencia en Hungría. Esa masa militar fue despachada con el fin de proteger los intereses de la dinastía en los confines orientales contra diferentes clases de desafíos: primordialmente contra la expansión otomana en Hungría; y en segundo plano contra el otro pretendiente, el rey Juan de Szapolyai y en tercer plano para consolidar el poder de los Austrias en los territorios conquistados, donde ciertos oligarcas querían aprovecharse de la larga guerra civil entre los dos pretendientes al trono de San Esteban. Al seguir esta lógica, se vislumbra también la estrategia de los Austrias al ubicar las compañías de los Tercios Viejos enviados a Hungría: entre 1526-1543 la mayoría de los hispanos en Hungría se hallan en castillos que protegen la ruta de los ejércitos otomanos hacia la sede real de Viena, (Zagreb-Croacia, Esztergom, Visegrád, etc.); incluso en 1529 los encontramos también entre los defensores de Viena. Durante los períodos de la consolidación interna (en otras palabras, luchas contra oligarcas) los situamos en expediciones por el norte (Hungría Superior, Ciudades de Mina, gran parte de actual Eslovaquia), en el condado de Trencsén (Trenčín, Eslovaquia), 1545; en los castillos y ciudades como Csábrág (Čabradský Vrbovok, Eslovaquia),1549; Murány (Moran, Eslovaquia), 1549; y Kassa (Košice, Eslovaquia), 1538/1539. Luego, después de la muerte del rey Juan, el gobierno de Fernando intentaba unificar las dos partes del reino (Reino de Hungría y Principado de Transilvania). Las compañías de mercenarios españoles, parte del ejército real y participantes activos de estas expediciones aparecen en la mayoría de los castillos en la parte oriental de Hungría (Szolnok) y en Transilvania (por ejemplo Temesvár, Lippa -actualmente Timișoara y Lipova, Rumanía-). Incluso, uno de los motines más documentados en la historia de Hungría también está relacionada con los 400

27. Pálffy, 1997, p. 71

28. En este capítulo resumo brevemente algunos resultados presentados en mi libro sobre Carlos $V$ y Hungría. Detalladamente ver Korpás, 2008b. 
españoles que, huyendo de Transilvania, se amotinaron en 1553 cerca de Pozsony (Bratislava, capital de Eslovaquia) y caminaron hacia Viena para recibir la paga retrasada ya más de un año y medio ${ }^{29}$.

En resumen, tenemos constancia de la llegada de siguientes tropas:

1. 3.000 españoles (2.000 españoles y 1.000 vizcaínos) a partir de una fecha desconocida, probablemente 1528 o $1529^{30}$.

2. En 1529 unos cuantos cientos de ellos defendieron el castillo de Zagreb contra los partidarios de Szapolyai ${ }^{31}$. Ese mismo año los españoles de Zagreb fueron llamados a Viena y formaron parte de los defensores de la ciudad durante el asedio de 1529. En esa lucha heroica participaron 700 españoles ${ }^{32}$.

3. En 1530 el marqués del Vasto fue encargado de reclutar a 1.500 italianos y a 1.000 españoles para ayudar en la lucha del rey Fernando I por la hegemonía en Hungría, pero ni del Vasto, ni los 2.500 españoles e italianos llegron a Hungría, aunque tenemos informaciones de que cierta parte de la fuerza se unió posteriormente al ejército real en Hungría ${ }^{33}$.

4. Formaban parte del ejército imperial 10.000 españoles y 10.000 italianos durante la expedición otomana contra Viena, en 1532, aunque parece que solo pocos de ellos cruzaron la frontera entre Austria y Hungría. Una obra menos conocida de Lope de Vega, El cerco de Viena por Carlos V relata de manera más ficticia que verdadera los acontecimientos, mencionando algunos protagonistas verdaderos como Carlos V, Fernando I, Antonio de Leyva, el marqués del Vasto, Giovanni Baptista Castaldo, etc.

5. Como consecuencia del tratado de Várad (Oradea, Rumanía) entre los dos pretendientes a la corona de San Esteban, los dos reyes: Fernando I y Juan I Szapolyai, el marqués del Vasto fue encargado otra vez de despachar 2.000 españoles del tercio viejo de Lombardía para ejercer en la

29. Sobre el motín de 400 infantes hispanos ver Korpás, 2005, pp. 379-398. La documentación del motín se halla en: ÖStA HHStA Ung. Akten Allg. Akten Fasc 70. Konv. A y Konv. B.

30. Carlos V al marqués del Vasto, Augsburgo, 27 de junio 1530: «por agora no se ha de traer mas gente de alla porque con esta y con los infantes españoles que estan en Hungria que son otros dos mill y otros mill españoles y vizcainos que iban y con la que mas sera manaester que se provea de aca se ha de hazer la guerra», AGS, Diversos Despachos, leg. 1557, fol. 233. Matía del Marigliano en su carta fechada desde Buda a 19 de enero de 1531 a Camillo Ursino, conde de Manupolio escribe que la ciudad húngara fue cercada por el ejército real de Fernando I, contando unos 12.000 soldados, incluyendo mercenarios de origen italiano, español y alemán. AGS, Estado Francia, leg. K 1483, fol. 69.

31. Sobre los acontecimientos del asedio de Zagreb ver la crónica de Nicolaus Istvánffy, Historiarum de rebus Ungaricis libri XXXIV.

32. Ver Oppl y Rudolf, 1997, pp. 58-64.

33. Fernando I a María de Hungría, Praga, 25 de marzo de 1530. En Bauer y Lacroix, 1937, t. II/2, pp. 618-620. También: Alonso de Santa Cruz: Crónica de Carlos V, t. IV, cap. 17: «y asi partió el Emperador de Mantua camino de Alemania y en el camino mandó ir a la gente de guerra a Hungría por estar en mucha necesidad el Rey D. Fernando, porque admeás de la guerra ordinaria que el turco le daba, le hacia gran guerra el vaivoda Luis Grite, un hijo de Andrea Grite, duque de Venecia». 
ejecución del acuerdo y para socorrer a los dos reyes de Hungría amenazados por la venganza otomana. Como consecuencia del motín de los españoles durante el asedio de Monferrato, parte del tercio fue despachado a Hungría y otra parte a Sicilia. Según la crónica de Quesada, el tercio encabezado por el maestre de campo Morales caminó hacia Hungría e incluso muchos de ellos se ahogaron en el río Inn, mientras la otra parte enviada a Sicilia fue encargada de juntarse con el tercio de Francisco de Sarmiento en Castelnuovo (Herceg Novi, Bosnia y Herzegovina). Esa última fuerza luego tuvo un fin trágico y heroico a la vez: cayeron muertos o en prisión después del feroz asedio encabezado por Khaireddin Barbarroja en $1539^{34}$.

6. Según Martin de Cerezeda, en 1541 encargaron a otro ejército imperial de 3.000 soldados que caminara a Hungría. En mayor parte fueron italianos, incluyendo ciertas compañías españolas, y la tropa fue encabezada por Gian Giacomo dei Medici35. Esa tropa en 1542 formó parte de la expedición fracasada de Joachim von Brandenburg para recuperar Buda, caída en manos otomanas un año antes.

7. En 1545, 2.400 españoles fueron llevados a Hungría por el maestre de campo Álvaro de Sande y lucharon contra los oligarcas húngaros quienes se aprovecharon del vacío de poder en el norte de Hungría, en el condado de Trencsén, parte de actual Eslovaquia. El mismo tercio un año después fue llevado a Alemania para luchar en la guerra de Esmalkalda y cumplió un papel muy importante derrotando a Juan Federico de Sajonia en la batalla de Mühlberg en 1547. Álvaro de Sande personalmente tenía una carrera militar muy importante: a él se le atribuye la fundación del Tercio Viejo de Lombardía, después de su expedición a Hungría y a Alemania, luchó varias veces contra los otomanos en la desastrosa expedición de Gelves en 1560 y en 1565, junto con Ascanio della Corgna (Cornia en forma latina), quien lideraba el desembarco de los tercios imperiales para liberar Malta del asedio otomano. Fue el gobernador de Milán entre 15711573 y uno de sus soldados era Miguel Cervantes de Saavedra ${ }^{36}$.

8. Aunque Álvaro de Sande tenía más fama en España y era desconocido en Hungría; el español más conocido en Hungría era el maestre de campo

34. el embajador Figueroa a Carlos V, Genoa, 22 de septiembre de 1538. «He visto como Vuestra Magestad havra holgado que el marques del Gasto aya embiado en Hungria dos mill españoles y tengo aviso que haviendose enbarcado en el rio Despruche para yr a Viena se havian homegado en el, Nuestro Señor aya miserocordia de sus animas y creo que el serenissimo rey de romanos havra holgado on los demas porque es gente muy luzida». En otra carta del mismo Figueroa figura: „que ya era partido los II U infantes que iva a Vngria y que segun lo que scrive el serenissimo rey de romanos llegaria a buen tiempo porque el vayvoda le havia embiado a pedir socorro». AGS, Estado Genoa, leg. 1371, fols. 11 y 18. Ver García Cerezeda, 1873-1876, libro II, pp. 141-144; Sandoval, 1955, libro III, p. 55.

35. García Cerezeda, 1873-1876, lib. 3, p. 31: «Mandose (marqués del Vasto-ZK) pasar en Hungría 3.000 italianos en favor de su hermano el rey de romanos, los cuales pasaron con Juan Jacobo de Médicis, marqués del Marignano».

36. Korpás, 2008a, pp. 199-210; Muñoz de San Pedro, 1955. 
Bernardo de Aldana. Su tercio de 1.400 españoles luchó en un periodo muy intenso de la historia de Hungría, cuando el rey Fernando I intentó por segunda vez - después del mencionado tratado de Várad, 1538- unificar las dos Hungrías en posesión cristiana, mientras la parte central, con Buda, permanecía en mano otomana. Aldana y sus soldados hispanos participaban en diferentes expediciones contra oligarcas húngaros en el norte del país (1548-1549), en la construcción del castillo de Szolnok (1550-1551) y también en las luchas antiotomanas en Transilvania (1551-1552). El resto del tercio, unos 400 españoles, se amotinaron en 1553 -causando mucho temor y preocupación por la corta distancia entre Pozsony (Bratislava, capital actual de Eslovaquia) y Viena ${ }^{37}-$.

Los tercios viejos en Hungría servían a los intereses dinásticos. De un total de 10.000-13.000 a la vez luchaban solo unos 1.400-3.000 españoles en Hungría y en la mayoría de los casos pasaron un lapso de 1-3 años en el país. Según los años formaban el 10-20\% del ejército real. Su tarea era -como la de las otras naciones del ejército real- proteger los intereses de la casa de Austria en Hungría y de tal manera contribuían a que Hungría no cayera fuera de la «Universitas Christiana» y no compartiera la suerte de otras naciones cristianas que se encontraban en el sur. Cabe destacar que teniendo en cuenta la importancia militar de los tercios españoles e italianos en el sistema militar europeo de aquel entonces, su presencia en Hungría en una proporción tan significativa, refleja la importancia estratégica del reino dentro del sistema de soberanía de la Casa de Austria. A la vez tenemos que llamar la atención sobre el hecho de que esa gran cantidad de personas llevaba muchas informaciones a su vuelta al seno de la Monarquía Católica, con lo que a nivel de historia personal introducían los sucesos de Hungría no solo a nivel de la gran política, sino a la vida cotidiana de los españoles. Según mi planteamiento, este es el factor básico y más importante que conducía a los autores del Siglo de Oro a escribir piezas sobre Hungría en tal proporción. Claro, aparte de esa creación personal de sensación de cercanía, influían otros factores, ya mencionados, como los enlaces dinástico-políticos o la tradición de la lucha anti-otomana tanto en España y en Hungría. Pero sin las experiencias personales de miles de españoles, hubiera sido bien difícil para los dramaturgos y escritores -con el intento de influir el gusto del público- presentar y fomentar la verosimilitud de temas tan lejanos como lo húngaro.

Las informaciones sobre Hungría y sus habitantes ofrecían una combinación temática que fácilmente servía para enriquecer la fantasía literaria: la mezcla de lo católico con las guerras civiles internas (tanto en el aspecto religioso como en el político) y también con la imaginada lujuria musulmana, sin olvidarnos de la caballería cristiana y de las luchas contra los otomanos, hostis naturalis de la Cristiandad. Algo muy excitante para un escritor, un poeta de aquel entonces, pues se halla en un lugar atractivo, fascinante, y socialmente inquietante a la vez. 
En breve, podemos subrayar que el público español del Siglo de Oro estaba familiarizado con los acontecimientos de Hungría, a causa de las relaciones de sucesos, y de la microhistoria de los muchos españoles en servicio militar o diplomático por Europa Central. La política dinástica y otros conceptos ideológicos como la «Universitas Christiana» o la lucha contra el «enemigo natural» de la Cristiandad enriquecían el nivel de las historias personales, creando de tal modo espacio para aquellas obras literarias donde el especial interés por lo húngaro era ubicado e integrado ligera y verosímilmente.

Y antes de terminar, un detalle más: aparte de la moderna interpretación historiográfica sobre la importancia de la contribución de los diferentes reinos de los Austrias tanto por el oeste como por el este, para proteger la dinastía y junto con ella a Hungría también, merece la pena mencionar que la permanencia de los españoles dejó ciertas huellas muy especiales también en Hungría. Mostrando el lado menos agradable de la vida de los mercenarios, la nuestra es una de las escasas naciones donde los mercenarios que luchaban durante los siglos XVI-XVII fueron mencionados por el código jurídico de aquel entonces: como consecuencia de las infinitas protestas de los húngaros por los saqueos de ciertos castillos realizados por los españoles, las leyes del año 1546 del Corpus luris Hungarici mencionan en el artículo 47 que los daños y las deudas causados por los españoles deberían ser indemnizados y los españoles reducidos a la orden ${ }^{38}$.

\section{BIBLIOGRAFÍA}

\section{Archivos}

Archivo General de Simancas (=AGS)

Diversos Despachos, Legajo 1557

Estado Alemania, Legajo 636

Estado Francia, Legajo K1483

Estado Genova, Legajo 1371

Österreichisches Staatsarchiv, Haus, Hof und Staatsarchiv Ungarische Akten

Allgemeine Akten (=ÖStA HHStA Ung. Akten Allg. Akten) fasciculus 55, fasciculus 70.

\section{Publicaciones}

Aguirre Landa, Isabel, «La correspondencia de Fernando de Austria conservada en el Archivo General de Simancas», en Socialización, vida privada y actividad pública de un Emperador del Renacimiento. Fernando I. 1503-1564, Alfredo

38. Corpus luris Hungarici, anno 1546, art. XLVII. 
Alvar Ezquerra (ed.), Madrid, Sociedad Estatal de Conmemoraciones Culturales, 2004, pp. 287-307.

Bayerle, Gustav, "One Hundred Fifty Years of Frontier Life in Hungary», en From Hunyadi to Rákóczi: War and Society in Late Medieval and Early Modern Hungary, J. M. Bak y B. K. Király (eds.), New York, Columbia University Press, 1982, pp. $227-242$.

Bocsi, J. Péter, «Hungría en el teatro de Lope de Vega», Revista de Literatura, $31.61 / 62,1967$, pp. 95-103.

Corpus luris Hungarici (1526-1608), Budapest, Franklin Társulat, 1899.

Csejtei, Dezső, «La presencia de Ortega y Gasset en Hungría entre 1928 y 1945», Revista de Hispanismo Filosófico, 13, 2008, 53-74.

Cuesta Astobiza, José Ramón, Epistolario político de Juan Alonso de Gámiz secretario destacado a la Corte del emperador Carlos V, en el Archivo Histórico Provincial de Álava, Vitoria, Diputación Foral de Álava, 2002.

Dávid, Géza y Pál Fodor (eds.), Ottomans, Hungarians, and Habsburgs in Central Europe: The Military Confines in the Era of Ottoman Conquest, Leiden/Boston, Brill, 2000.

Escribano, Martín Fernando, La expedición del maestre de campo Bernardo de Aldana a Hungría en 1548, Madrid, Miraguano, 2010.

Etényi, Nóra G., Hadszíntér és nyilvánosság, Budapest, Balassi Kiadó, 2003.

García Cerezeda, Martín, Tratado de las campañas y otros acontecimientos de los ejércitos del emperador Carlos V en Italia, Francia, Austria, Berberia y Grecia, Madrid, Imprenta Aribau, 1873-1876.

González Cuerva, Rubén, «El prodigioso príncipe transilvano. La larga guerra contra los turcos (1593-1606) a través de las relaciones de sucesos», Historia Moderna, 28, 2006, pp. 277-299.

Gómez, Jesús, «Historia y ficción «la corona de Hungría»», en La Dinastía de los Austria. Las relaciones entre la Monarquía Católica y el Imperio, José Martínez Millán y Rubén González Cuerva (eds.), Madrid, Polifemo, 2011, vol. 3, pp. 1947-1963.

Gregorowicz, Dorota, Uno sguardo da Iontano. L'immagine della Polonia secondo le relazioni dei nunzi apostolici nella seconda metà del Cinquecento, Manuscrito publicado en la Universidad de Trento, 2013.

Gutiérrez Gil, Alberto, «Hungría como espacio mítico en las comedias palatinas de Lope de Vega, Mira de Amescua y Rojas Zorrilla», Revista sobre teatro áureo, 7, 2013, pp. 218-234.

Hopp, Lajos, Az «antemurale» és «conformitas» humanista eszméje a magyar-lengyel hagyományban, Budapest, Balassi Kiadó, 1992. 
Istvánffy , Nicolaus, Historiarum de rebus Ungaricis libri XXXIV, Colonia Agrippina, 1622.

Kelenik, József, «The Military Revolution in Hungary. Ottomans, Hungarians, and Habsburgs in Central Europe», en Géza Dávid y Pál Fodor (eds.), Ottomans, Hungarians, and Habsburgs in Central Europe: The Military Confines in the Era of Ottoman Conquest, Leiden/Boston, Brill, 2000, pp. 117-159.

Knoll, Paul W., «Poland as Antemurale Christianitatis in the late Middle Ages», The Catholic Historical Review, 40.3, 1974, pp. 381-401.

Korpás, Zoltán, «Húngaros en obras de Lope de Vega: las fuentes históricas del drama El rey sin reino», Anuario Lope de Vega, 5, 1999a, pp.119-127.

Korpás, Zoltán, «Egy spanyol zsoldosvezér levelei a XVI. Század közepén vívott magyarországi háborúkról. Adalékok Bernardo de Aldana magyarországi tevékenységéhez (1548-1552)», Fons, 6.1-2, 1999b, pp. 3-129.

Korpás, Zoltán, «La frontera oriental de la Universitas Christiana entre 1526-1532», en Carlos V. Europeísmo y Universalidad. El Congreso Internacional. Granada, 1-5 de mayo, 2000. Vol. 3. Los Escenarios del Imperio, Juan Luis Castellano y Castellano y Francisco Sánchez-Montes González (eds.), Madrid, Sociedad Estatal para la Conmemoración de los Centenarios de Felipe II y Carlos V, 2000a, pp. 321-337.

Korpás, Zoltán, «La correspondencia de un soldado español de las guerras de Hungría a mediados del siglo XVI. Comentarios al diario de Bernardo de Aldana (1548-1552)», Hispania, LX/3, 206, 2000b, pp. 881-910.

Korpás, Zoltán, «Las luchas antiturcas en Hungría y la política oriental de los Austrias», en Fernando I, 1503-1564. Socialización, vida privada y actividad pública de un Emperador del Renacimiento, Alfredo Alvar y Friedrich Edelmayer (eds.), Madrid, Sociedad Estatal de Conmemoraciones Culturales, 2004, pp. 335-370.

Korpás, Zoltán, «Ami a magyarországi hadjárat után történt. Bernardo de Aldana és a spanyol zsoldosok sorsa 1552 után», Fons, 12.3, 2005, pp. 379-398.

Korpás, Zoltán, «Álvaro de Sande hadjárata Trencsén vármegyében-1545», en Redite ad Cor. Tanulmányok Sahin-Tóth Péter emlékére, Lilla Krász y Teréz Oborni (eds.), Budapest, ELTE Eötvös Kiadó, 2008a, pp. 199-210.

Korpás, Zoltán, V. Károly és Magyarország, Budapest, Századvég Kiadó, 2008b.

Korpás, Zoltán, «l. Ferdinánd levelezése V. Károly melletti követével, Juan Alonso de Gámizzal (1542-1556)», Fons, 16.2, 2009, pp. 249-306; 16.3, 2009, pp. 309372.

Kunčević, Lovro, «The rhetoric of the frontier of Christendom in the diplomacy of renaiisance Ragusa (Dubrovnik)», Dubrovnik Annals, 17, 2013, pp. 37-68. 
Laferl, Christopher, Die Kultur der Spanier in Österreich unter Ferdinand I. 15221564. Wien, Böhlau Verlag, 1997.

Martí, Tibor, «Datos sobre las relaciones entre la nobleza hispana y los estados húngaros en la época de la Guerra de los Treinta Años», en Nobleza hispana, nobleza cristiana: la Orden de San Juan. Actas del congreso internacional Alcázar de San Juan, 1-4 de octubre de 2008, Manuel Rivero Rodríguez (ed.), Madrid, Editorial Polifemo, 2009, pp. 473-526.

Martí, Tibor, «Los antecedentes del viaje a Roma del Cardenal Péter Pázmány en 1632», en La Dinastía de los Austria. Las relaciones entre la Monarquía Católica y el Imperio, José Martínez Millán y Rubén González Cuerva (eds.), Madrid, Editorial Polifemo, 2011, vol. 1, pp. 175-205.

Martínez Ruiz, Enrique, Los soldados del rey. Los ejércitos de la Monarquía Hispánica (1480-1700), Madrid, Editorial Actas, 2008.

Martorell, Joannot y Joan de Galba Martí, Tirant lo Blanc, ed. David H. Rosenthal, New York, Shocken Books, 1984.

Monostori, Tibor, «Transilvania en el horizonte político-ideológico de Saavedra Fajardo», en Saavedra Fajardo y su mundo, Res publica-Revista de filosofía política, 19, 2008a, pp. 351-366.

Monostori, Tibor, «Tres cartas inéditas en el Archivo de Estado de Viena», en Diego de Saavedra Fajardo: Rariora et minora, José Luis Villacañas Berlanga (ed.), Murcia, Editorial Tres Culturas, 2008b, pp. 303-315.

Muñoz de San Pedro, Miguel, Don Álvaro de Sande, cronista del desastre de los Gelves, Badajoz, Diputación Provincial de Badajoz, 1955.

Oppl, Ferdinand y Karl Rudolf, España y Austria, Madrid, Ediciones Cátedra, 1997.

Pálffy, Géza, «A török elleni védelmi rendszer néhány alapkérdése a XVI. Század első felében», en Tivadar Petercsák (ed.), Hagyomány és korszerúség a XVIXVII, Században, Eger, Dobó István Vármúzeum, 1997, pp. 59-74.

Pálffy, Géza, The Kingdom of Hungary and the Habsburg Monarchy in the Sixteenth Century, Boulder, Colorado, Social Science Monographs-Wayne, New Jersey, Center for Hungarian Studies and Publications, Inc.-New York, Distributed by Columbia University Press, 2009a.

Pálffy, Géza, «The Bulwark and Larder of Central Europe (1526-1711)», en On the Stage of Europe. The millennial contribution of Hungary to the idea of European Community, ed. Ernő Marosi, Budapest, Research Inst. for Art HistoryBalassi Kiadó, 2009b, pp. 100-124.

Perjés, Géza, «The Zrínyi-Montecuccoli Controversy», en From Hunyadi to Rákóczi: War and Society in Late Medieval and Early Modern Hungary, J. M. Bak y B. K. Király (eds.), New York, Columbia University Press, 1982, pp. 335-349. 
Rodriguez Villa, Antonio, El emperador Carlos V y su corte según las cartas de don Martín de Salinas, embajador del infante don Fernando (1522-1539), Madrid, Establicimiento Tipográfico de Fortanet, 1903-1905.

Sambrian, Oana Andreia: «La imágen de Transilvania en El prodigioso príncipe transilvano y El rey sin reino de Lope», en Cuatrocientos años del arte nuevo de hacer comedias de Lope de Vega. Actas selectas del XIV congreso de la asociación Internacional de Teatro Español y Novohispano de los Siglos de Oro, Germán Vega García y Luengos y Héctor Urzáiz Tortjada (eds.), Valladolid/ Olmedo, Olmedo Clásico, 2010, pp. 947-955.

Sandoval, Prudencio de, Historia de la vida y hechos del Emperador Carlos V, máximo, fortísimo, rey católico de España y de las Indias, islas y tierra firme del mar océano, Madrid, Madrid, Ediciones Atlas, 1955.

Szilas, László, Alfonso Carrillo jezsuita Erdélyben (1591-1599), Budapest, Magyar Egyháztörténeti Enciklopédia Munkaközösség, 2001.

Veress, Endre, Carrillo Alfonz jezsuita-atya levelezése és iratai: 1591-1618, Budapest, Magyar Tudományos Akadémia, 1943.

Zachar, József (ed.), The Hungarian Hussar. An Illustrated History, Budapest, Corvina Books, 2000. 
